\title{
EL COTO VEDADO COMO FUNDAMENTO DE LA DESOBEDIENCIA CIVIL
}

\author{
Luis Caroca Páez y Sebastián Cabello Osorio* \\ Universidad de Atacama, Chile \\ naxoturvina@msn.com; cloudstraif@msn.com
}

\begin{abstract}
"Quien se guiase por la lógica podría inferir de una gota de agua la posibilidad de la existencia de un Océano Atlántico o de un Niágara sin necesidad de haberlos visto u oído hablar de ellos".
\end{abstract}

Sherlock Holmes

RESUMEN: En este trabajo hemos querido hacernos cargo de una materia de una antigua data y de poco desarrollo dogmático en América Latina, que es de suma importancia tomando en cuenta al pasado cercano que tenemos en común las comunidades americanas en el siglo XX, y el gran desarrollo que ha sostenido en Europa desde la antigüedad hasta la actualidad. Pasando por una rica gama de estudios, que han dado lugar a fundamentos contrapuestos entre muchos que la consideran esencial a cualquier Estado de Derecho, en un ideal pluralista y democrático; y otros que la niegan protegiendo a un Estado fuerte y cohesionado. Analizamos también el concepto del "coto vedado" de Ernesto Garzón Valdés, que nos sirve de base conceptual a nuestra descripción del problema. Comenzamos analizando, desde una perspectiva extrema, las consecuencias de la desobediencia civil, cuando el Estado no ha sido capaz o simplemente ha ido en contra de los derechos fundamentales, entregando algunas razones de las acciones de parte de los sujetos en contra del Estado, que ha devenido en un avasallador poco razonable e irresponsable con los derechos y la Constitución, dando una

* Estudiantes, pregrado de Derecho, Facultad de Ciencias Jurídicas de la Universidad de Atacama, 2010. 
visión panorámica y descriptiva de los distintos conceptos que se manejan en relación a la desobediencia civil, algunas características, fundamento histórico y su importancia.

Palabras clave: desobediencia civil, democracia, derechos fundamentales.

\begin{abstract}
In this work we meant to take charge of a former subject and little dogmatic development on Latin America, which is very important taking into consideration the recent past that Americans communities have on $20^{\text {th }}$ century, and the big growth that has sustained on Europe from ancient times to present day. Passing through a rich range of studies, which have given contrasting basis on many who think it is essential for any state based on the rule of law, in a pluralist and democratic ideal; and others who deny it defending a united and strong state. We also analyze the "Coto Vedado" concept from Ernesto Garzón Valdés, this idea is useful for a conceptual base of our problem's description. We began analyzing using an extreme view of civil disobedience's consequences, when the state has not been able or simply it has gone against fundamental rights, giving some reasons of the actions who people commit against the state, it have became in an overwhelming, irresponsible and not very reasonable with rights and the constitution, giving a panoramic and descriptive vision of the different concepts that are used in relation to civil disobedience, also some characteristics, an historic foundation and its importance.
\end{abstract}

Keywords: civil disobedience, democracy, human rights.

\title{
1. ARGUMENTOS A FAVOR DEL COTO VEDADO Y LA INCLUSIÓN DE LA ESFERA DE LO INDECIDIBLE
}

Existen significativamente varias razones por las que optamos en utilizar el término de Garzón Valdés y no el de Luigi Ferrajoli, que tiene un interesante contenido, muy similar por cierto con el que nosotros adscribimos ${ }^{1}$.

1.1 El núcleo de los derechos. Ambos se refieren al límite de la democracia o "la regla de la mayoría", donde, como explicamos al comienzo de este trabajo, se constituyen los límites sustanciales de la democracia, a esto último también se refiere un acápite que reservamos especialmente para su explicación, y decir por qué consideramos que "la esfera de lo indecidible" pertenece al "coto vedado", por lo tanto no resultan contradictorios.

Con todo, esto no significa que no aceptemos el concepto acuñado por Ferrajoli, sino todo lo contrario, lo aceptamos y lo incluimos dentro del concepto de Garzón Valdés, y es el motivo que nos indujo a justificar el estudio general de ambos, y con ello entregar algunas diferencias y reflexionar en torno a su utilidad conceptual. 
1.2 Principios y derechos que la democracia no puede afectar. Los derechos que están sustraídos de la decisión mayoritaria son los mismo derechos fundamentales una vez reconocidos constitucionalmente, poseyendo un carácter contra-mayoritario y legitimante del ordenamiento jurídico ${ }^{2}$.

\section{ALGUNAS CONSIDERACIONES EN TORNO AL COTO VEDADO, LA DEMOCRACIA Y EL LEGÍTIMO DERECHO AL EJERCICIO DE LA DESOBEDIENCIA CIVIL}

Günter Düring, presupone un significado subjetivo del concepto derecho fundamental. Los derechos fundamentales o esenciales son derechos que están conectados a la idea de naturaleza humana, siendo derechos que universalmente pertenecen a todo individuo de la especie humana. Los derechos tienen así un carácter suprapositivo. Para el autor en comento, "la dignidad humana expresa una especificación material independiente de cualquier tiempo y espacio, que consiste en considerar como perteneciente a cada persona un espíritu impersonal, que le capacita para adoptar sus propias decisiones sobre sí mismo, sobre su conciencia y sobre la configuración del mundo que lo rodea”. Así la cláusula del contenido esencial de los derechos, se incluye como una positivización de la dignidad humana inafectable y del contenido inviolable de los derechos humanos ${ }^{3}$. Tentativamente diremos que este concepto adolece de una serie de divergencias terminológicas, pero para efectos de nuestra exposición la tendremos en cuenta y la usaremos principalmente para así explicar mejor el llamado principio de la intangibilidad de los derechos fundamentales y el concepto de Garzón Valdés. La base de los derechos fundamentales es independiente de la democracia que es, en consecuencia, el límite, que nace precisamente del núcleo del derecho al cual ni aun la regla de las mayorías puede inmiscuirse, y más aún considerando que los derechos para las democracias actuales constituyen el núcleo básico donde es posible la vida en sociedad y donde solo le quepa al Estado el reconocimiento de tales derechos. Es

Por una parte, ambos conceptos no son contradictorios, lo que significa que los dos pueden incluir los mismos derechos y principios, pero con la salvedad (y esto constituye la gran diferencia) que el "coto vedado" tiene una dinámica distinta a la de la "esfera de lo indecidible", ya que de hecho contiene más derechos que los que trae el concepto de Ferrajoli, toda vez que su formulación pertenece al objeto de estudio de las ciencias políticas; no así como la "esfera de lo indecidible" que pertenece a un concepto jurídico, como lo explica el mismo Ferrajoli cuando trata de diferenciar a los términos antes mencionados. Dinámica del coto vedado y la limitación positiva de la Democracia en la teoría de la esfera de lo indecidible, y el contenido esencial de los derechos. El "coto vedado" y el "territorio inviolable" de Norberto Bobbio son términos prácticamente homogéneos, pero ambos como son conceptos de teoría política, son principios de legitimación política externa al ordenamiento (dentro de sí están los derechos fundamentales), y es esta característica la que le permite su dinámica, para ir reformándose de acuerdo a las nuevas necesidades que van surgiendo con la evolución de la sociedad. En esto hay una explicación dada por G.V. respecto del contenido formal de "coto vedado", nos dice que existen necesidades básicas generales a cualquier sociedad, y por otra parte las necesidades secundarias, que dependen del desarrollo de cada sociedad individualizada, generalmente se refieren a derechos que actualmente se encuentran en desarrollo, como por ejemplo los derechos sociales, o los de carácter medioambiental.

3 Nogueira Alcalá, Huberto. Dogmática constitucional -1a edición- Talca, Chile: Editorial Universidad de Talca, 1997, pp. 173-174. 
justamente el valor imperativo de estos derechos y la acción de reconocimiento, que le da sentido inmediato al ideal de los derechos fundamentales, y que este concepto de coto vedado existe como valor justificatorio de tales entidades, toda vez que su función es excluir de toda consideración democrática, de quien detente para sí la adhesión de las mayorías, trayendo en consecuencia de su actuar la ilegitimidad de sus actos. Ciertamente esta descripción del coto vedado, solo es referente obligatorio al Estado como actor exclusivo en sus asambleas deliberativas, y que en ningún caso podría utilizarse como instrumento del Estado en contra de sus súbditos, es decir, ya que este, como es bien sabido, es la primera decisión política de una sociedad o si se quiere, el acto in concreto del contrato social, lo que en resumidas cuentas le da a la comunidad la oportunidad de reformar su propia organización.

Sin embargo, esto no está libre de objeciones, pero el coto vedado nos servirá de gran ayuda en este trabajo, para poder explicar de forma más o menos clara el concepto de rebelión contra la opresión, y el papel que juega dentro de la democracia constitucional actual. Dicho sea de paso, que la tarea inicial de los Estados modernos está en el esfuerzo por asegurar a la comunidad que tenga a su cargo la máxima realización material y espiritual, con pleno respeto a los derechos y garantías, pero no solo aquellos que están positivados en el documento político (la Constitución), sino también como es de esperar en todo aquello que resulte indispensable para el mantenimiento de la dignidad de las personas (o las necesidades básicas o primarias). Entonces surge aquí la duda a propósito del derecho a la revolución contra la opresión. ¿En qué sentido le concierne al Estado reconocer el ejercicio de este derecho, cuando está siendo efectivamente ejercido por la sociedad, sin caer en la crisis de reprimir todo aquello que pugne con el aparato estatal? Esta pregunta, sin duda, es bastante compleja, y evidentemente por razones de extensión no es posible responderla exhaustivamente, no obstante lo interesante es dejar en boga la dificultad que entraña tan anacrónica discusión, tanto histórico-filosófica (sobre todo en la variedad de pensadores ilustrados, inclusive viajando más atrás en el tiempo podemos encontrar vestigios de ella en Platón, Aristóteles, Tomás de Aquino, y otros más recientes), y finalmente, el aspecto tanto político, jurídico y económico. Nuestro interés se sitúa principalmente en la importancia que concita para sí el valor que tiene este derecho, el que probablemente no resulte del todo agradable para aquellos defensores acérrimos de los gobiernos más autoritarios, debido a que el reconocimiento explícito de tal prerrogativa podría ser razón suficiente para la revolución interna en democracias débiles, que generalmente se sirven de constituciones claramente presidencialista y de gran protección a la doctrina de la seguridad nacional.

Sin embargo, la polémica y posible dicotomía que surge, por un lado, de aquellos que sostienen que es más importante proteger al Estado (como único instrumento capaz de resguardar los derechos) y que tal revolución solo generaría inestabilidad política además de la poca seguridad de los mismos derechos; por otro, aquellos que adscriben en asegurar que 
este derecho (a la revolución contra la opresión) será necesario en la medida en que la necesidad social lo demande, y el Estado no sea lo suficientemente capaz de lograr, aun teniendo las posibilidades de asegurar la dignidad de sus habitantes.

Seguramente, muchos han de pensar que la primera opción resulta más viable, dada sus características de regularidad en las relaciones Estado-individuo (y por consiguiente es garantía suficiente al orden instrumental económico que sirve de pedestal a la organización social), pero su dificultad y principal crítica viene por el impedimento de reformar el orden institucional, trayendo consigo una lenta reingeniería constitucional y, por ende, una crisis social de toda índole. Pues bien, como señala Juan Bautista Alberdi, padre intelectual de la Constitución argentina, refiriéndose al papel que juega una Constitución para una sociedad, dice: "la carta de navegación del país, sin la cual este vagaría sin rumbo; y la creencia extendida en los meritos sublimes de algunas constituciones o los efectos catastróficos de otras" ${ }^{4}$. Lo que nos deja este pequeño análisis, es que la guía de todo gobierno está suscrita a la Constitución política, y si el mismo ente se aleja desproporcionadamente de los objetivos y alcances normativos de la Constitución, relegando así el valor ético de la actuación política, y con ello denostando el contenido esencial de los derechos. Se podría pensar que la obligatoriedad de los mandatos emitidos por el Estado adolecería de legitimidad y obligatoriedad moral, y que jurídicamente serían anulables de acuerdo a los adecuados instrumentos, tanto constitucionales como legales que hipotéticamente le asisten a la comunidad. A esto surgen nuevas interrogantes igualmente interesantes de abordar, como por ejemplo: ¿Qué sucede si este Estado avasallador de los derechos, no respeta los instrumentos de anulación como acciones y recursos procesales, o la decisión tomada por el Tribunal Constitucional? ¿Acaso no existe alguna justificación moral para el ejercicio de la desobediencia civil? ¿Habría que justificar y aceptar el gobierno déspota y renunciar a la cuota de libertad que se supone que tienen los sujetos? ¿Debe ser remplazado el gobierno desde el día en que abdicamos de nuestra democracia? O finalmente, ¿Cuál es el valor moral de obedecer a un Derecho que emana de una autoridad injusta o ilegítima?

Evidentemente estas preguntas resultan algo exageradas en una situación extrema donde el Estado no respeta ni aun los tratados internacionales que versen sobre derechos humanos, y así no sancionar los crímenes contra la humanidad y de esta índole, resultando impunes en un Estado de Derecho que ha perdido su fundamento inicial ${ }^{5}$. Nuestra idea central no es dar respuesta a tales interrogantes, sino más bien generar más dudas que razonablemente deberían encontrar respuesta en la plausibilidad de los argumentos. Este argumento ha sido abandonado sin respuestas convincente por parte de los doctos en este tema.

Nino, Carlos Santiago. La constitución de la democracia deliberativa. Barcelona, Espańa: Editorial Gedisa, 1997, pp. 30-31.

5 Véase. Verdugo, Mario, et al. Derecho constitucional. Tomo I -1a edición- Santiago, Chile: Editorial Andrés Bello, 1994. pp. 122 y ss. 
Sin embargo, nos parece imprescindible abordar este asunto desde el punto de vista del contenido esencial de los derechos, o "garantía de garantías" como lo llama Böckenförde, el ya analizado coto vedado, y la obligatoriedad moral del Derecho.

\section{CONSIDERACIONES SOBRE LA OBLIGATORIEDAD MORAL DEL DERECHO EN SU VERTIENTE DE LA DESOBEDIENCIA CIVIL}

El teorema conceptual basado en la obligatoriedad moral del Derecho, resulta de suma complejidad y cualquier intento por delimitar su tratamiento resultaría infructífero, por lo menos en este trabajo, sin embargo, sería interesante realizar tal empresa en el futuro. Es por esto que antes de iniciar nuestra reflexión advertimos que señalaremos sumariamente algunos planteamientos que podrían servir de base conceptual a la temática desarrollada en este escrito, sin que con ello se agote su tratamiento teórico y filosófico y pueda eventualmente ser mejorado en un futuro. En un primer acercamiento podríamos decir que el Derecho, en sus orígenes, tiene una innegable vinculación con la moral y que aquella vinculación o lazo que une por un lado al Derecho con todo su aparato coercitivo, con las valoraciones y el conjunto de reglas morales. Esto es igualmente omnicomprensible al fenómeno de la desobediencia civil, ya que es ahí donde la moral cubre con su manto la mayor parte de las justificaciones, y que aquellas razones más trascendentales que sociológicamente pueden darse a la hora de entregar las suficientes conclusiones para la justicia de la actuación de los sujetos sublevados. Si pensamos que el Estado de Derecho es una construcción política legítima en su origen, a diferencia de otras teorías políticas, las tesis contractualistas han tomado cuerpo y realidad en los llamados procesos constituyentes. Como el Estado es producto del acuerdo socialmente reconocido, su finalidad es proteger tal acuerdo, con la sola disposición que la ley le entrega en virtud de la voluntad general, que le ha dado para actuar en concordancia con sus atribuciones y correspondientes límites, que vienen dados por los distintos aparatos institucionales que el mismo Estado posee, lo que contemporáneamente son los límites a la soberanía. Sin embargo, como anteriormente dijimos, existe una gama más o menos amplia de preguntas, en la cual nos pusimos en el contexto de: ¿Qué sucedería si el Estado y sus instituciones no cumplen con el fin determinado en el primer acto político de instauración jurídica, y sus concurrentes responsabilidades con la protección y conservación de la dignidad de las personas? Pues bien, estas preguntas quizás sean las más importante para arribar a una actuación contraria al Estado, evocando con ello la reforma de alguna regla o un conjunto de ellas, o la conquista de algún derecho aún no reconocido o en el extremo de los casos la instauración de un nuevo acto político originario, constituyendo con ello los fundamentos del nuevo orden jurídico y social que traería dicha actuación. 


\section{EVOLUCIÓN HISTÓRICA DE LA DESOBEDIENCIA CIVIL}

Desde algún tiempo la democracia ha sido uno de los sistemas político de gobierno más usado en la actualidad, por medio de la representación y la decisión soberana de las mayorías, y el consenso vendría siendo la clave para la toma de decisiones en sociedad. Aun asi $i^{6}$, en los países occidentales ciertas formas de actuación política distintas de la democracia han coincidido en salirse de los cauces normales de la democracia representativa, calificándose como "acciones directas". Una de estas acciones directas es la llamada desobediencia civil. Autores a lo largo de las épocas han intentado justificar la desobediencia desde múltiples puntos de vista, sin embargo, la crítica que se les ha hecho ha sido su falta de elaboración en cuanto a su concepto. Aun así, a estos teóricos no se les puede negar que su importancia radica en llevar este modelo teórico a la realidad, cuestión que ha influido substancialmente en el desarrollo de su propia sociedad, y en la historia humana. En este apartado nos dedicaremos a analizar los modelos teóricos de John Locke, Henry David Thoreau, Mahatma Gandhi y Martin Luther King.

\subsection{JoHN LOCKE7 Y EL IUS RESISTENDI}

Respecto a los actos arbitrarios y déspotas del gobernante, establece la reacción que debe tener la sociedad en su conjunto, la cual es la "resistencia" a los actos que atentan contra el bien común de la sociedad. Este clima hostil se ve restablecido por el poder que ejerce el pueblo, el que tiene la soberanía expresada en el Parlamento, el poder más importante para Locke dentro de los tres poderes", a lo que considera "La doctrina del poder en el pueblo". Ahora bien, Locke limitaba este derecho a resistirse contra la autoridad, ya que sería oponible cuando la fuerza fuera "injusta e ilegal", y a su vez esté cerrada la "apelación judicial", lo que le daría el carácter de ultima ratio, además, no deben ser hechos pequeños y aislados, deben ser hechos arbitrarios o ilegales que afecte a la sociedad en su conjunto, caso contrario podría ser confuso y azaroso. Podríamos decir que se confundiría con el concepto de poder constituyente originario, ya que podría llegar hasta la resistencia contra el soberano, que concluiría en un nuevo orden jurídico-político, pudiendo implantar a un

6 Rodríguez Paniagua, José María. "La desobediencia Civil”, en Revista española de Derecho Constitucional <en línea> España, Centro de Estudios Político Constitucionales, Año 2 Núm. 5, Mayo-agosto 1982, p. 95, disponible en la World Wide Web: < http://dialnet.unirioja.es/servlet/articulo?codigo=249981>

7 John Locke (1632-1704) pensador inglés, padre del empirismo y el liberalismo moderno. En sus ensayos sobre el gobierno civil, reconoce la ley natural y hace de ella el punto de partida de sus consideraciones. Como hombre empírico, cristiano, y partidario de un derecho natural, creía que había derechos seńalados en la ley natural que eran comunes a todos los hombres por igual. Partidario en un principio del luteranismo, creía en una ley natural que prohibía la disolución de la sociedad y el gobierno. Sin embargo, pocos años después, comenzó a desarrollar una crítica al derecho divino regio en su obra principal: "Ensayo sobre el gobierno civil"; señalando los fines y obligaciones del gobierno legítimo, principalmente lo que es la propiedad y mantener un clima de convivencia pacífica de la sociedad.

8 Friedrich, Carl Joachim. La Filosofía del Derecho -8a edición-. México D.F., México: Editorial Breviarios del Fondo de Cultura Económica, 2004, p. 154. 
nuevo gobernante. Es cierto que a Locke le preocupaba que la sociedad pudiera disolverse mediante está resistencia, y que la cláusula para que ello no ocurriere era que la soberanía siempre residía en el pueblo. Aun así, que los gobernantes pudieran ser derrocados por las armas, y aceptar la fuerza en todas sus manifestaciones para ir en contra de la opresión, prácticamente no tendría límites, cualquier dirigente o grupo de poder podría aprovecharse de esta situación. Pero aun así, y aunque esta expresión de resistencia -como último recurso, armado y hasta violento- es el derecho a la revolución, es, sin embargo, "el derecho natural que forma parte de la ley natural, y que solo se ejerce cuando el orden existente se está disolviendo”.

\subsection{Henry David Thoreau ${ }^{9}$ y la Anarquía pacífica}

Partidario del pacifismo y la no violencia, concebía la idea de que el Estado no debía tener más poder que los propios ciudadanos, proponiendo hasta la abolición de todo gobierno, y del mismo Estado ${ }^{10}$. Sin embargo, y a pesar que el autor trata una desobediencia pacífica y no violenta, la práctica demostraría una revolución mucho más violenta y destructiva de lo esperado, ya que el postulado teórico casi anárquico de no pagar impuestos, acabaría con el Estado y con el mismo Derecho, lo que sería un total y auténtico "acto de rebelión revolucionario". En este caso, el problema estaría en la práctica del modelo teórico, ya que en un principio se consideraría como desobediencia civil, sin embargo, su resultado lo define más como anarquía. Aun así, esta expresión de desobediencia tendría el mismo sentido que Locke, el cual es modificar el ordenamiento jurídico injusto y restablecer la paz social.

\subsection{Mahatma Gandhi ${ }^{11}$ y la desobediencia Civil pasiva}

Gandhi usaba el concepto de desobediencia civil, distinto de la resistencia, ya que este último según él es "una expresión de débiles", no así el primer concepto de "no-cooperación",

9 H. D. Thoreau (1817-1862), agrimensor, naturalista y fabricante de lápices, defensor de la desobediencia civil. Durante su vida, experimentó la vida en naturaleza, por lo que pasó dos ańos viviendo en un bosque. Cuestionaba la idea de la guerra, filósofo y defensor de los derechos naturales y la desobediencia civil. La conciencia individual u objeción de conciencia sería para Thoreau, algo que trasciende a los fines del Estado, evitando de esta forma la realización del mal y la injusticia, esto ya que era férreo detractor a la entonces guerra que llevaba Estados Unidos en contra de México, rechazando el modelo esclavista que llevaba su país. Se negó a pagar impuestos, lo que lo llevó a ser detenido, y le sirvió de inspiración para su "Tratado sobre la desobediencia civil".

10 "Pero si es de tal naturaleza que te exige ser el agente de la injusticia que se hace a otro, entonces yo os digo: quebrantad el Derecho, haced de vuestra vida un freno, para parar la máquina (refiriéndose al Estado). Lo que yo tengo que hacer es procurar por todos los medios no prestarme a realizar el mal que condeno". Rodríguez Paniagua, José María. op. cit. (n. 6) p. 99.

11 Mohandas Karamchand Gandhi (1869-1948), abogado, pensador y político indio. Instauró nuevos métodos de lucha contra el dominio británico en las indias, tales como huelgas pacíficas, huelgas de hambre, y del rechazo a los movimientos armados, además de la total fidelidad a las ideas de la propia conciencia individual, tuvo como gran influyente las ideas de Thoreau. 
lo que suponía "la buisqueda de la verdad por el camino de la no-violencia" como opción constructiva. Esta no cooperación, indicaba una objeción o manifestación de la conciencia del individuo que podía llegar desde los procedimientos más simples y pacíficos, hasta los procedimientos más revolucionarios como el no pago de impuestos. Así, la desobediencia civil en Gandhi, constituía grados de desarrollo, siendo la desobediencia civil el grado inicial que comenzaba en la simple desobediencia pacífica como objeción de conciencia, hasta tomar medidas más extremas como lo sería las huelgas de hambre colectiva, o posturas más extremas como el no pago de impuestos ${ }^{12}$. Siempre será no violenta; aunque Gandhi no se cierra a la opción de utilizar la coacción directa ${ }^{13}$. Distinto a otros autores, fundamental el desplazamiento de la atención, "del contenido a las formas". El contenido podría ser importante, pero nada servía si la forma en cómo se realizaba, no crea una reflexión y cambio en quienes lo observaban y experimentan; además de exigir en algunos casos una extrema urbanidad, buenos modales. El fundamento es "un derecho propio o natural del ciudadano; de tal modo que no puede renunciarse a él sin dejar de ser hombre"14, lo que le daría el carácter de natural o derecho humano. Gandhi afirma que no puede adoptarse a la ligera, sino de manera muy limitada y con sólidos fundamentos, y debe ser razonable. "La desobediencia civil sería la llave del poder en manos de la soberanía social”15.

\subsection{Martin Luther King ${ }^{16}$ y el Poder Negro}

Su concepto de desobediencia civil es el que más se acerca al que tenemos hoy en día. La fundamentación de la desobediencia civil está relacionado con los postulados clásicos de San Agustín y Tomás de Aquino, los que expresaban "no puede ser ley la que no sea justa" y "no puede ser justa la que no se funde en la ley natural". El discurso y el pensamiento de Luther King, no buscaba resaltar este carácter o fundamentar esta ley natural, sino mostrar y demostrar los males que se estaban generado producto del estricto cumplimiento de las leyes

12 "La desobediencia civil es el rechazo de las disposiciones estatales; cuando este rechazo se extiende a todas ellas, al conjunto del Derecho estatal o del ordenamiento jurídico, tenemos la rebelión o revolución en sentido jurídico-político". RodRíguez Paniagua, José María. op. cit. (n. 6), p. 101. Gandhi tomó muchos postulados de Thoreau, entre ellos, el no pago de impuestos.

$13 \mathrm{Al}$ respecto, Gandhi señala: "Pero si la injusticia cometida es intolerable, es un derecho y un deber de toda nación y de todo individuo no someterse a ella... Si las leyes de un Estado han llegado a ser totalmente o en su mayor parte injustas, se justifica incluso la desobediencia civil completa, es decir, la rebelión”. Ibid., p. 102.

14 Gandhi, Mohandas. Non-violent Resistence. En: Rodríguez Paniagua, José María. op. cit. (n. 10), p. 102.

15 Rodríguez Paniagua, José María. op. cit. (n. 6), p. 103.

16 Martín Luther King (1929-1968) fue un pastor bautista que desarrolló una labor crucial en Estados Unidos al frente del movimiento por los derechos civiles básicos para los afroamericanos y para toda persona. Participó en numerosas protestas contra la guerra de Vietnam y la pobreza en general. También colaboró con protestas promoviendo el voto universal, siempre de manera no violenta y pacífica. Llevó a cabo diversas actividades políticas, dentro de las destacables están las protestas contra el apartheid estadounidense y la discriminación racial a través de medios no violentos, fue condecorado con el Premio Nobel de la Paz en 1964. Fue influenciado por Thoreau así como también por Gandhi. 
injustas, como es el caso de la discriminación racial ${ }^{17}$. En cuanto a su forma, debe ser no violenta, pública, con ausencia de odio, sometimiento a las penas que imponga el ordenamiento jurídico, también respetando el ordenamiento jurídico en bloque, y respetando las normas que regulan esta situación de desobediencia. Creemos que este sería el sentido que más se acerca al concepto que intentamos explicar y que debería utilizarse hoy en día, ya que va contra el poder político producto de la arbitrariedad o ilegalidad, lo que sería en los tiempos de Luther King, el "Poder Negro" contra la opresión injusta y arbitraria de la autoridad.

\subsection{Breve Mirada A LA DESObEDIENCIA CIVIL ACTUAL}

Hoy en día, la desobediencia civil se ve expresada en varias ONG así como protestas y movimientos a lo largo del mundo. No es coincidencia esto, ya que la historia ha demostrado una actualización y modernización de estos movimientos, con pleno respeto a la legalidad, las formas, carente de violencia, buscando la reflexión además de la corrección de las injusticias por parte de la autoridad. Su importancia es que han contribuido al desarrollo de los Estados, corrigiendo las desigualdades y cumpliendo un rol activo y fiscalizador hacia la autoridad. La expresión ya repetida: "Las grandes cosas se han conseguido históricamente por la fuerza y movimientos violentos" no es del todo cierta, estos autores si bien fueron arrestados, enjaulados y maltratados en algunos casos, siempre tuvieron el temple de buscar la paz interior y mostrar su descontento de manera pacífica y sin el uso de armas ni la fuerza.

\section{EXPLICACIONES TEÓRICAS RESPECTO AL TÉRMINO DESOBEDIENCIA CIVIL Y SU CONCEPTO ACTUAL}

Etimológicamente, y en nuestro hoy Estado de Derecho la desobediencia la entendemos como producto de un acto ilegal, y es civil ya que encuentra sus límites en la misma sociedad, en la misma cultura, y en las mismas costumbres. Esta infracción o violación ha de referirse contra toda legalidad estatal, es decir, a toda norma del ordenamiento jurídico. En cuanto a las limitaciones de la desobediencia civil, se limita con la propia legalidad en bloque, esto es, debe respetar y acatar este conjunto, así como las normas que también regulan esta situación ${ }^{18}$. Si bien va contra la legalidad en su conjunto, se somete a las normas

17 "La deformación del alma y el deterioro de la personalidad... no solo se le da al segregado un sentimiento infundado de inferioridad, sino también al que segrega un falso sentimiento de superioridad, que le hace ver al segregado como una cosa. Por lo que, la segregación no solo es mal desde el punto de vista político, económico y social, sino que también es injusta y pecaminosa desde el punto de vista moral”. KING, Martin Luther. Civil Desobedience Letter from Birmingham City Jail. En: Rodríguez Paniagua, José María. op. cit. (n. 6), p. 104.

18 Respecto a este punto, debemos señalar que el derecho a reunión se desprende del Art. 19 no 13 , que es efectivo siempre y cuando se respeten las disposiciones que lo regulan, por lo que la infracción a estas normas acarrea una sanción, situación que la desobediencia civil también respeta, lo que podría configurar una hipótesis de desobediencia civil reconocida implícitamente, así como también podría configurarse en el himno nacional, reconocido por nuestra Constitución en su artículo segundo. 
que lo regulan, y estando en conciencia de la sanción que acarrea la infracción a la norma que lo regula. Lo importante, más allá de si es contra una norma particular o contra todo el ordenamiento jurídico en su conjunto, es que esa autoridad haga un mal uso del derecho, de forma arbitraria o ilegal, caso en el cual también podría ir contra normas particulares.

\section{CARACTERÍSTICAS DE LA DESOBEDIENCIA CIVIL}

Es Postrera; ya que actúa una vez que se hace notoria o evidente la ilegalidad, abuso, o arbitrariedad ${ }^{19}$. Es decir, debe el acto de la autoridad ser manifiestamente injusto para la sociedad o un sector de ella como si no respetara el procedimiento de la Constitución y las leyes que se le imponen. No violenta; este requisito es fundamental para diferenciarlo de lo que es el terrorismo. La actuación debe ser lo más pacífica posible refiriéndonos al no uso de armas ni a la coacción directa de la fuerza ${ }^{20}$. Respetando la legalidad ${ }^{21}$; esta característica es fundamental para diferenciarlo de otros conceptos ya señalados. Al momento de desobedecer civilmente a la autoridad, debe respetar las normas legales que lo regulan. Fundamento político y/o jurídico; su finalidad podría ser tanto política - producto de las decisiones arbitrarias e ilegales- como jurídica -restablecer el imperio del Derecho-; por lo que podría revestir uno o ambos caracteres. Contra la legalidad; va contra la legalidad en su conjunto, o contra una(s) norma(s) del ordenamiento jurídico. Popular; ya que no es necesario que afecte, individualice o especifique la(s) persona(s) afectada(s). Directa; es decir, debe ser pública y manifiesta, y no como resultado de una acción que no tenía como objetivo causar una modificación del comportamiento o acto en la autoridad ilegal o arbitraria. Los medios siempre deben ir en coherencia con el resultado que se pretende, el cual puede ser un fin político y/o jurídico. Limite en la democracia; así como los derechos fundamentales pertenecen a la frontera de lo indecidible, como dice Ferrajoli, la decisión de las minorías también debe respetar la opción y decisión legislativa, lo que le daría su carácter de civil. Ultima ratio; se entiende frente a los actos arbitrarios o ilegales, pero una vez agotadas todas las instancias racionales y jurídicas del sistema. Hay otras instancias que pueden hacerse valer con anterioridad -como la judicial-, este sería un recurso último, frente a las demás vías ya agotadas. No escrito; primeramente le daría su carácter de derecho humano -mas no constitucional-. El hecho de que lo consideremos como no escrito, viene dado porque precisamente la democracia tiene por finalidad que las decisiones se tomen por esa vía y no por otra. De hecho, algunos

19 Podríamos expresar constitucionalmente esta característica en el articulo 19 No 2, "igualdad ante la ley" (en Chile no hay persona ni grupo privilegiado), y una expresión aún más contundente sería el articulo 19 no 19 "igual repartición de las cargas públicas", esto es, nadie está obligado a soportar cargas u obligaciones no permitidas por el sistema, es decir, de forma arbitraria o ilegal.

20 Mohandas Karamchand Gandhi nos decía: "No hay caminos para la paz; la paz es el camino".

21 Caravante Muntada, María José. Una revisión crítica de la desobediencia civil en la obra de J. Habermas. <En línea> Madrid, [Citado 12-13 marzo 2005] Disponible en la Word Wide Web: <http:// www.Uv.es/CEFD//11/ caravante.pdf>, p. 10. 
ordenamientos jurídicos de otras corrientes políticas distintas a la democracia tienen consagrado este derecho ${ }^{22}$, por lo que la tendencia es a no consagrarlo explícitamente. Creemos, sin embargo, que consagrarlo demostraría una sociedad madura y reflexiva en cuanto a estos temas. Aun así sería igualmente peligroso, por lo que una mala interpretación de esa cláusula de desobediencia, podría traer consecuencias desastrosas ${ }^{23}$. Así, y luego de señalar estas características, podríamos definir a la desobediencia civil en stricto sensu, en términos de John Rawls ${ }^{24}$, y dando nuestro propio concepto: Es Aquel derecho humano, postrero, que da pie a la acción no violenta, popular, directa, que procede una vez agotados todos los recursos en el ordenamiento jurídico, y que busca modificarlo por completo o alguna de sus normas, producto de la ilegalidad o arbitrariedad de una autoridad, restableciendo la paz social y/o el imperio del Derecho.

\section{CONSIDERACIONES FINALES SOBRE LA IMPORTANCIA DE LA DESOBEDIENCIA CIVIL}

Hoy en día "No se trata de la resistencia a un Estado injusto, sino de la desobediencia en el Estado de Derecho" 25 . Nos encontramos con la realidad del Estado Liberal distinto de lo que fue el Estado no sujeto a Derecho que podía ser resistido hasta violentamente por la sociedad. En el Pensamiento del Filósofo y Sociólogo Alemán Jürgen Habermas, el Estado de Derecho no significa un último estadio de evolución en la historia humana, todo lo contrario, es una construcción no acabada y en constante cambio. En palabras de Habermas: "La desobediencia civil se encuentra justificada siempre que se propugne una idea de Estado de Derecho orientado hacia su propia realización y no se tome como único criterio de Derecho Positivo". La desobediencia civil ha sido utilizada a través de las épocas como un método crítico, para corregir los errores de los Estados. Sirve hoy como herramienta de corrección del Estado Liberal de Derecho, cuando todas las otras opciones se encuentran agotadas, este postrero recurso, como lo es la desobediencia civil, es la clave en los Estados Liberales para un mejor desarrollo de la Democracia, cuestión que se le ha dado escaso desarrollo, siendo una fundamental herramienta crítica y constructiva de las sociedades actuales. Creemos que este tema tan poco tratado en Latinoamérica, es de vital importancia como

\footnotetext{
22 Así, la Constitución cubana, en su artículo 43, hace plena referencia a la revolución y los derechos conquistados por esta.

23 Aun así, existen casos muy particulares, en los que es reconocida la rebelión contra la opresión como derecho humano. En la Ley Fundamental de Bonn, se consagra en su artículo 20.4 lo que sería el derecho a resistencia, que le da la facultad al ciudadano alemán, "Contra cualquiera que intente eliminar este orden, todos los alemanes tienen el derecho de resistencia cuando no fuere posible otro recurso". Es decir, tienen el derecho a rebelarse; a ejercer el derecho a la resistencia. Esto es, emplear métodos antijurídicos, y no respetar la legalidad.

24 John Rawls lo define "como un acto público, no violento, consciente y político, contrario a la ley, cometido con el propósito de ocasionar un cambio en la ley o en los programas de gobierno", seńalando también como rasgo específico que el desobediente civil actúa "dentro de los límites de fidelidad a la ley".

25 Carabante Muntada, José María. op. cit. (n. 21), p. 4
} 
herramienta crítica para sacar a flote los problemas del Estado Liberal. El ejercicio de este derecho de forma respetuosa y no violenta, resulta una demostración de madurez por parte de la sociedad. La problemática y lamentable crisis en la que nos encontramos al desconocer total o parcialmente un derecho, que nos pertenece desde siempre, pero que debido a factores de todo tipo no conocemos y menos aún, sabemos el valor que contiene y la realeza de su importancia en el desarrollo de nuestra sociedad, y la responsabilidad moral que tienen todos los actores sociales que no se han hecho parte del desarrollo final, que traería como consecuencia una sociedad más justa, igualitaria, democrática y respetuosa con los derechos humanos. Podríamos tener la razón en todo este arduo trabajo, como estar totalmente equivocados, pero hemos ganado una cosa, una pregunta. Ahora, es momento que el lector decida: ¿Desobedecer o no desobedecer? He ahí la cuestión. 


\section{REFERENCIAS BIBLIOGRÁFICAS}

Biagini, Hugo. "El Ius Resistendi en Locke", en Revista de estudios políticos. No 2, $1978<$ En línea>, disponible en World Wide Web: <http://dialnet.unirioja.es/servlet/articulo?codigo=1273720>

Carabante Muntada, María José. Una revisión crítica de la desobediencia civil en la obra de J. Habermas. <En línea> Madrid, [Citado 12-13 marzo 2005] Disponible en la Word Wide Web: <http:// www.Uv.es/ $\mathrm{CEFD} / / 11 /$ caravante.pdf>

Ferrajoli, Luigi. La esfera de lo indecidible y la división de poderes, en Estudios constitucionales. <En línea>, Universidad de Talca, Centro de Estudios Constitucionales de Chile, año 6 no 1, 2008, [Citado 14 julio 2010] Disponible en la Word Wide Web: <http://www.cecoch.cl/docs/pdf/revista_ano6_1/Laesfera17.pdf>

Friedrich, Carl Joachim. La Filosofía del Derecho-8a edición-. D.F, México: Editorial Breviarios del Fondo de Cultura Económica, 2004

Garzón Valdés, Ernesto. Algo más acerca del coto vedado. <En línea> [Citado 19 julio 2010]. Disponible en World Wide Web: <http://www.cervantesvirtual.com/servlet/SirveObras/01361620813462839088024/ cuaderno6/Doxa6_12.pdf>

Nino, Carlos Santiago. La constitución de la democracia deliberativa, -1a edición-. Barcelona, España: Editorial Gedisa, 1997

Nogueira Alcalá, Huberto. Dogmática constitucional. -1a edición-. Talca, Chile Editorial Universidad de Talca, 1997.

PÉrez Lisicic, Rodrigo, "Reflexiones en torno a la noción de poder constituyente", ponencia, XXXVI Jornadas Chilenas de Derecho Público: Reformas constitucionales 2005 un ańo después, Santiago, Chile: Universidad de Chile, 2005.

Rodríguez Paniagua, José María. "La desobediencia Civil”, en Revista española de Derecho Constitucional <En línea> España, Centro de Estudios Político Constitucionales, Año 2 Núm. 5, Mayo-agosto 1982, disponible en la Wold Wide Web: < http://dialnet.unirioja.es/servlet/articulo?codigo=249981>.

Verdugo, Mario, et al. Derecho constitucional. Tomo I -1a edición-. Santiago, Chile: Editorial Andrés Bello, 1994. 